\title{
El rol del profesional de la información y la información audiovisual y multimedia como servicio del centro de recursos para el aprendizaje (CRA)
}

\section{María Teresa Rosas de Maidana}

\author{
Recibido: 19.10.2011
}

Aceptado: 1.12.2011

\section{Resumen}

Una vez más se trata de que la escuela, los centros educativos, incorporen o tomen prestados recursos existentes en la cultura con el fin de enriquecer o mejorar los procesos de enseñanza aprendizaje. En este caso las propuestas sobre el potencial de los recursos audiovisual y multimedia, en contextos en los que la actividad está basada en los procesos de comunicación, son tan deslumbrantes, que casi se puede hablar de verdadera urgencia, por parte de las instituciones educativas el incorporarlos en casi todos sus niveles, no sin cierta precipitación, cuando todavía son escasos los resultados de investigaciones que pudieran iluminar este proceso que involucra a la información audiovisual y multimedia en el Paraguay.

Así se puede decir que el mundo es en color, que pronto será multimedia casi toda la información digital disponible, y que el beneficio de su traducción o paso a conocimiento y aprovechamiento está basado en la creciente capacidad de las redes y los soportes que se presentan en el entorno tecnológico

Hoy en el país se busca dar calidad educativa, las bibliotecas y sus servicios son el primer eslabón para el desarrollo, en pos a ello se formulan programas que permitan incursionar en el proceso tecnológico a los educandos y en este marco la inquietud manifiesta de presentar un estudio cierto sobre los prolegómenos para el uso efectivo de la información audiovisual y multimedia en los nuevos soportes y el logro del compromiso de la reforma con el profesional de la información como referente del cambio.

\section{Palabras clave}

Bibliotecarios-Formación profesional, Bibliotecas-Servicio Audiovisual

\section{Abstract}

Once again it is the school, educative centers, incorporate existing resources or from borrowing in the culture to enrich and improve teaching and learning processes. In this case the proposals on the potential of audiovisual and multimedia resources in contexts in which the activity is based on communication processes, are so dazzling, you can almost speak of a true emergency, by the educational institutions incorporated in almost all levels, with some precipitation, while they are still few research results that could shed light on this process involving audiovisual and multimedia information in Paraguay. 
So it can be said that the world is in color, soon to be media almost all digital information available, and that the benefit of a translation or step knowledge and use is based on the increased capacity of networks and media that have in the technologicalenviroment.

Today the country is looking to provide quality education, libraries and their services are the first step for development, and pursue it are formulated programs to move into the technological process to learners in this context expresses concern to present a study on the run for the effective use of audiovisual and multimedia information in the new media and the achievement of the commitment to reform the information professional as a benchmark for change.

Keywords

Librarians Professional Training, Libraries Audiovisual Service

\section{INTRODUCCIÓN}

Hoy en el Paraguay, como en otros países del entorno está presente la aplicación de los recursos tecnológicos en la escolarización de niños y jóvenes tomando como elemento primero la aplicación de la información audiovisual y multimedia. Por ser ésta la dispuesta en programas educativos de la reforma cuya clave radica en la formación del pensamiento crítico y reflexivo de los educandos. Y en este entorno se llama al profesional de la información como elemento activo del cambio.

Así se presenta esta investigación como un aval descriptor de las 53 bibliotecas escolares (Centro de Recursos para el Aprendizaje-CRA), de la ciudad de San Lorenzo. Esta ciudad es tomada como centro de la labor por su consideración como la culta ciudad universitaria, la tercera en orden de población (320. 018 habitantes) y con un grupo de 0 a 14 años de 96.800 personas con un rango del $93,9 \%$ de educandos ${ }^{2}$.

En el trabajo, se observa la necesidad de guiar a los usuarios en entornos que no sobrecarguen la información e inexperiencia en las alternativas al escoger una información cierta. Es allí donde es manifiesto el rol del bibliotecario, proporcionando servicios que permitan para abordar carencias del medio educativo en los escenarios de aprendizaje, en alternativas para una educación útil y significativa. Se testimonia así el vació que produce la incertidumbre del conocimiento en el área de tecnología y educación, merced a los resultados obtenidos en la investigación, facilitando valores ciertos para aplicación e impacto de las nuevas tecnologías.

\section{TECNOLOGÍA EN PARAGUAY}

La apertura a las tecnologías y al mundo digital es un desafió aquí y en todo el mundo, a este se suma el poseer y concretar la nueva escuela pública, avalada por el Ministerio de Educación (MEC) con el Centro de Investigación e Innovación Educativa en la definición de programas para el logro del nuevo modelo educativo, propuesto en el plan 2020 de la reforma educativa.

\footnotetext{
${ }^{2}$ Dirección General de Estadísticas, Encuestas y Censos. Principales indicadores: población y viviendas, 2002
} 
Con esta perspectiva cabe interiorizar ¿el profesional de la información que papel le es otorgado en el cambio? ¿Está preparado para el desafío?

\section{La Reforma Educativa en Paraguay}

El plan estratégico de educación Paraguay 2020 reza en su consigna "Actualizando bases para un pacto social", y da respuestas al incorporar acciones a las transformaciones de la sociedad y los avances del conocimiento.

El objetivo clave de la reforma es la formación del pensamiento crítico y reflexivo de la ciudadanía tomando dentro de sus fines la adquisición de conocimientos, la capacitación de técnicos y profesionales (Bibliotecarios) y la investigación científica y tecnológica Ya se encuentra en disposición la Reforma 2024 desde mayo de 2009, que se constituirá en el documento marco de la política educativa paraguaya con la denominación "Hacia el centenario de la Escuela Nueva de Ramón Indalecio Cardozo" En el caótico devenir de la educación con bajo presupuesto, el logro es un desafío.

Existen numerosos proyectos que encaran los desafíos planteados en la reforma para los recursos de información y conectividad: Atlas de la diversidad, Escuela Viva Hekokatúva, Al rescate de las computadoras, Educación media con énfasis en nuevas tecnologías, Aulas mentes (jóvenes y adultos, docentes), Portal educativo nacional Arandú Rape son ejemplos de las iniciativas nacionales. Estas propuestas de una casi nula continuidad, es decir comienza, cesa, inicia, en un repetir sin hito.

La existencia de un portal denominado Arandúrape que aplica en su contenido la información audiovisual y multimedia, con imágenes, sonidos, videos (mini clip, en formato WMV), para el usuario, en apoyo a la cultura y educación del país, expresamente denomina el link de acceso Audiovisuales. Aún así se avanza en forma lenta y en un relego de partes, ya que la capacitación no es efectiva, la difusión es nula. La propuesta para el avance postula la política educativa como estrategia de inclusión social, plasmado hoy en un programa denominado “Una computadora por niño" implementado por la Fundación Paraguay Educa. ${ }^{3} \mathrm{Al}$ día de hoy no cuenta con presupuesto suficiente para la reprisa en otras comunidades.

Capacitaciones

El nivel básico de entrenamiento para el conocimiento del hardware y software esta dado para bibliotecarios, docentes e involucra a los padres y el entorno socio-económico del estudiante, aplicado en el departamento de cordillera, se evalúa la incorporación de las XO en competencias sociales, describiendo experiencias y que la comunidad local encuentre en la investigación las evidencias necesarias para la definición de políticas que promuevan la calidad educativa con equidad Pero es sabido que sin un apoyo monetario los modelos desaparecen quedando el mero esfuerzo para el acto que en relevancia será historia.

Analizando que el proceso de la enseñanza audiovisual y multimedial ha cambiado los espacios educativos tradicionales en el alcance de espacios laborales y educativos, los métodos de enseñanza varían del conductivismo al desarrollo cognitivo y el aporte mayor del

\footnotetext{
${ }^{3}$ www.arandurape.edu.py
} 
constructivismo, ubicando al alumno en el centro potenciando sus habilidades para construir conocimiento. $Y$ en este cambio se ve la permuta de los recursos multimediales diseñados con enfoques constructivistas con el creciente empleo de la multimedia e hipermedia en un ambiente de interconexión y cooperación. Esto es una realidad parcial, un ideal del paso a paso.

Con la reforma el bibliotecario tiene una doble función, por un lado como especialista en el tratamiento, la organización, la recuperación y difusión de la información y como conocedor de los recursos de información destinados a los usuarios en la oportunidad de otorgar mejores condiciones para el acceso y uso de dichos recursos a toda la comunidad educativa, cabe inquir ¿̇están los bibliotecarios escolares preparados para asumir esta misión?

Tendría que el bibliotecario escolar llenar el vacío que da la ausencia de materiales bibliográficos específicos para el área curricular y el mayor acercamiento a los conocimientos, despertado el espíritu investigativo del educando. Cuan difícil es la situación, dado que en mayoría, el líder, el gerente, el director o como quiera llamarse al bibliotecario escolar no es más que un personal a punto de jubilarse, un bachiller sin sapiencia en el área de la Bibliotecología o una persona que no se identifica con su profesión y actividad.

Ante lo expuesto en los párrafos anteriores cabe preguntar

¿Cuál es el rol del profesional de la información para que la información audiovisual y multimedia beneficie al usuario en logro del pensamiento crítico y reflexivo?

¿Poseen las bibliotecas uso y recursos multimediales para brindar este servicio a los usuarios en pos del logro del pensamiento crítico y reflexivo?

¿Está el profesional de la información en capacidad de brindar el servicio en base a la información audiovisual y multimedia?

¿Puede el profesional de la información aprovechar la tecnología del mundo globalizado y reducir en la medida de las posibilidades la brecha entre los informados ricos e informados pobres?

¿Cómo lograr que un usuario interprete, critique y reflexiones sobre la información dada?

¿Es posible llegar a la plena alfabetización informacional de los usuarios por medio de la información audiovisual y multimedia?

¿Qué impacto otorga la aplicación Tecnología, información y conocimiento en la comunidad educativa en atención a la reforma?

¿Qué grado de relevancia tiene la información proporcionada por estos medios en el apoyo al currículo institucional?

\section{JUSTIFICACION}

En el fortalecimiento de la reforma educativa la información audiovisual y multimedia facilita la incorporación del proceso del aprender a aprender estimulando los sentidos otorgando a la 
enseñanza la motivación suficiente para el crecimiento educativo integral tomando en positivo el uso de las herramientas que las tecnologías facilitan.

Hay también otros muchos elementos desplegados en beneficio de la efectividad de la información; por ejemplo, las tecnologías semánticas. Sin duda, asignar el significado correcto a los significantes constituye un reto cardinal. Esta tecnología permite la utilización de los materiales multimedia caracterizados por integrar distintos lenguajes, información o documentos: texto, imágenes, sonido, animación, fragmentos de vídeo, consultas on line a bases de datos o aplicaciones informáticas.

$Y$ en este cambio se ve la permuta de los recursos multimediales diseñados con enfoques constructivistas con el creciente empleo de la multimedia e hipermedia en un ambiente de interconexión y cooperación.

Siendo esta la evolución, las actuales reformas educativas iniciadas en muchos países en las últimas décadas, han incorporado a sus currículos (todo aquello que el medio escolar ofrece al alumnado como posibilidad de aprender), entre sus muchas innovaciones tecnológicas, la cuestión de la transversalidad.

El término "transversalidad" se enmarca en la nueva concepción curricular que, ante la crisis de la función normativa de la escuela que pretendía alcanzar conductas formales, neutras y susceptibles de ser generalizadas, aboga por un modelo en el que los contenidos se constituyen en el eje estructurador de objetivos y actividades educativa, otorgando al Bibliotecario escolar gran responsabilidad como gerente y dinamizador de la Biblioteca escolar.

Lo propuesto con anterioridad volcará la investigación en beneficio de la comunidades educativas (alumnos/as, padres, docentes) fortaleciendo los contenidos curriculares implementados y verificando el impacto que la utilización de herramientas TIC dan a la comunidad.

Fortalecer el currículo en este proceso implica el estudio con todos los sentidos en fijación significativa del aprender a aprender y en una instancia global a toda la comunidad san lorenzana, para constituirla en el eje emblemático de las aplicaciones de la tecnología en educación. En este empeño deben aunar esfuerzos los profesionales de la información, junto a profesores y educadores. Expresiones ciertas que en el país no se ejecutan en verdad, la dispersión de las actividades, la poca comunicación, la capacitación deficiente el bajo presupuesto educativo va en detrimento de la política educativa en el desarrollo innovador de la reforma.

Esto se puede volcar en positivo dando un protagónico al profesional de la información desde los Centros de Recursos para el Aprendizaje (CRA) como formadores desde el nivel inicial para lograr el lema que dice que la educación es un compromiso de todos. $Y$ este es un esfuerzo cooperativo, el bibliotecario, no sólo es proveedor de fuentes de información, sino activo protagonista en la formación de competencias en información y apoyo del cambio educativo, otorgando la posibilidad al desarrollo personal y profesional de los usuarios fortaleciendo el capital intelectual de la comunidad educativa. Se evidencian los paradigmas que presentan el 
aprendizaje continuo y renovado, son desafíos en el acelerado ritmo de los cambios estrechando en su relación con la alfabetización informacional que debe realizarse desde la educación inicial abarcando la forma y el contenido del currículo educativo.

En pos a cualidades y actitudes se logrará que los usuarios adquieran un aprendizaje significativo, recordando que cuando se aplican todos los sentidos en el proceso de enseñanza aprendizaje se facilita el entendimiento y comprensión de la temática permitiendo esto, el aprendizaje significativo que según Liset Santoyo "El aprendizaje significativo es aquel proceso mediante el cual, el individuo realiza una metacognición: 'aprende a aprender', a partir de sus conocimientos previos y de los adquiridos recientemente logra una integración y aprende mejor

Así se proyecta en el nuevo espacio en beneficio del usuario 


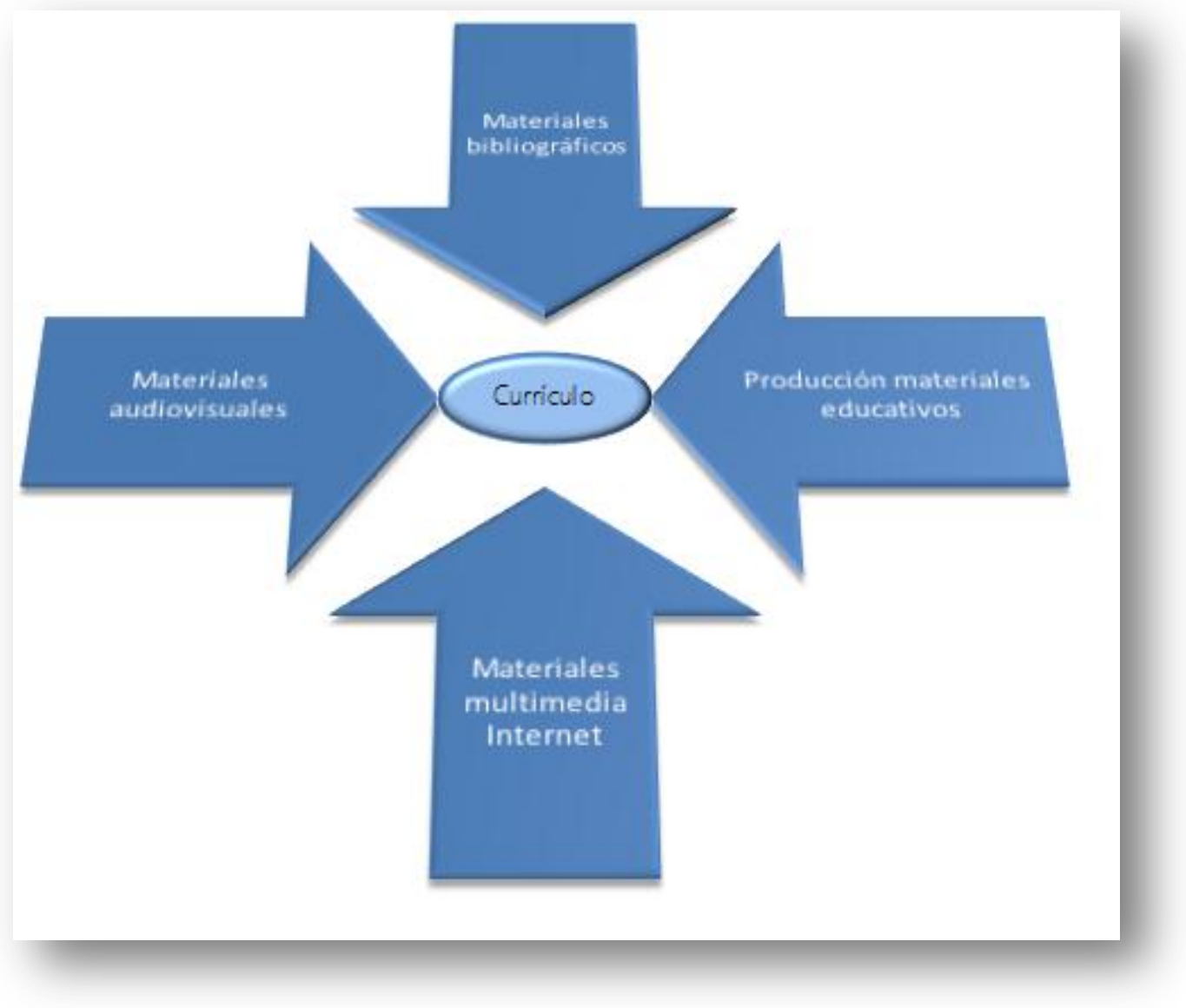

Figura 1: mapa del nuevo currículo

Permitirá lo proyectado marcar acertadamente la dirección del desarrollo programático en apoyo al currículo escolar, por ende se pude ir incorporando las innovaciones educativas de la reforma con garantía de éxitos proponiendo estrategias para ser aplicadas a favor del uso de la información audiovisual y multimedia.

Desde las bibliotecas escolares se puede alentar a participar más en programas de alfabetización informacional, iniciando con el uso efectivo de las herramientas audiovisuales y multimediales. También este trabajo puede servir como una lista de verificación para evaluar los programas en biblioteca donde ya se han instrumentado.

Con la aplicación del uso de la información audiovisual y multimedia se puede generar estrategias integrales para englobar dificultades de las áreas del currículo (ciencia, física, matemática...). Se orienta también en el uso y manejo de las tecnologías que luego permitirán el desarrollo efectivo de la investigación e incorpora las dinámicas de trabajo con las innovaciones tecnológicas.

Y con estándares bien constituidos se puede establecer un registro de uso y utilidad en la comunidad educativa en proyección a aplicación de innovaciones adecuadas a la reforma atendiendo el entorno del desarrollo. 
Porque la aplicación de la información audiovisual y multimedia ofrece el soporte adaptativo a la implementación de sistemas tecnológicos, orientados a la integración efectiva del currículo educativo y aportando un soporte para la ejecución de sistemas tecnológicos orientados a la integración del currículo educativo conforme lo ofrecen los pares internacionales.

Su aportación en los nuevos conceptos de innovación y desarrollo dará el reconocimiento al dominio educativo con interacción y aplicación de diseños tecnológicos confeccionados conforme la necesidad de los usuarios y disposiciones inherentes a las autoridades nacionales.

La flexibilidad de la metodología a ser aplicada para la identificación de enfoques permitirá la repriza y ejecución del estudio en otras ciudades del país, tornando en un futuro próximo, la aplicación país en un referente de innovación tecnológica-educativa.

\section{OBJETIVOS}

\section{Objetivo General}

- Fundamentar el rol del bibliotecario escolar y el uso de la información audiovisual y multimedia con las habilidades de búsqueda de información de forma crítica y reflexiva.

\section{Objetivos Específicos}

- Valuar la otorgación de la información audiovisual y multimedia dada a la comunidad educativa en pos a la alfabetización informacional.

- Comprobar el apoyo al currículo escolar en el servicio dado con la información audiovisual y multimedia.

- Relevar el impacto de la información audiovisual y multimedia en los usuarios y la comunidad educativa.

- Cuantificar las bibliotecas que prestan servicios de información audiovisual y multimedia

- Disponer de un marco planificado para la educación del usuario en pos de los postulados de la reforma y el apoyo al currículo.

\section{FUNDAMENTO TEORICO}

Hay que recordar que, al comienzo de los años 80, en el panorama de la información, el conocimiento y la comunicación, podía hablarse por separado (como si no tuvieran todavía mucho que ver)de sectores de actividad tales como la Telecomunicación, la Informática, la Prensa, la Televisión, la Enseñanza, la Industria Editorial, la Producción Audiovisual, la Fotografía, la Electrónica doméstica, y quizá otros; pero el avance de la tecnología electrónica e informática iría abriendo expectativas de desarrollo de todos los sectores. ${ }^{4}$

Fue en esos primeros años de la década cuando comenzó a popularizarse el PC (el ordenador personal) y el consiguiente concepto de interactividad o comunicación hombre-máquina; pero también en aquellos años las tradicionales redes de conmutación telefónica electromecánica

\footnotetext{
${ }^{4}$ La tecnología y el mundo digital :desafíos pedagógicos para la nueva escuela
} 
habían previsto ya digitalizarse para dar respuesta a las emergentes necesidades de conmutación y transmisión de datos. A mediados los años 80 los términos como ofimática, red digital de servicios integrados, datáfono, fax..., y también el buzzword "multimedia". Veinte años después, no sólo hablamos, en general, de la "industria multimedia", sino que se trabaja ya en pro y en pos, de una relación más efectiva entre las fuentes de información y sus usuarios; esto incluye nuevos elementos, tales como las herramientas multimedia que nos permiten incorporar audio, animación y vídeo. Además de manejarnos con las herramientas ofimáticas habituales, incorporamos nuestro perfil profesional a las nuevas destrezas multimedia, mediante los cursos correspondientes.

\section{Información audiovisual}

La expresión "arte audiovisual" empieza a usarse en Estados Unidos en los años 1930 con la aparición del cine sonoro. Sin embargo, empieza a teorizarse en Francia durante la década de los años 1950 para referirse a las técnicas de difusión simultánea. El concepto audiovisual significa la integración e interrelación plena entre lo auditivo y lo visual para producir una nueva realidad o lenguaje. La percepción es simultánea. Se crean así nuevas realidades sensoriales mediante mecanismos como la armonía, los completos y el refuerzo.

Se puede definir audiovisual, como un adjetivo que hace referencia al conjunto de audio y vista y se utiliza frecuentemente a formato de difusión de contenido.

La utilización más frecuente del concepto está vinculada al formato de difusión de contenidos que se vale de imágenes ópticas acompañadas por grabaciones acústicas. Un material audiovisual es visto y oído por el espectador. ${ }^{5}$

Lo audiovisual puede existir de tres maneras diferentes, audiovisual natural, audiovisual parcialmente tecnificado y audiovisual artificial.

Y con la aplicación innovadora los recursos visuales y audiovisuales se pueden facilitar en plataforma Youtube o Flicker la información en apoyo a áreas temáticas y los contenidos curriculares en eLearning.

\section{Información multimedia}

A finales de la década de 1920 se lo nombraba a todo lo que se trasmite a través de los sentidos. ${ }^{6}$ La televisión, el Internet y el cine son ejemplos de lo mencionado, tomando sonido más imagen en un montaje, plasmado en un DVD o cinta.

\section{CONTENIDO $=$ INFORMACION}

Estos términos se puede decir que brindan igualdad, ya que se toma la proposición:

Forma/contenido $=$ se entiende como difundir o presentar un mensaje ${ }^{7}$.

\footnotetext{
${ }^{5}$ Tecnología y educación. Consultado el 6 ago 2011. Disponible en : http://definicion.de/audiovisual/

${ }^{6}$ CEBRIANH.,M. Información audiovisual y educación. Madrid: UNED,1995. P 485-495

${ }^{7}$ Tecnología educativa Consultado el 6 ago 2011. Disponible en: www.foroactivo.net
} 
Y en el desglose se pude decir que la multimedia es el uso de textos y gráficos, recursos tradicionales en una computadora y a esto se suma el conocimiento de las distintas posibilidades que ella en su desarrollo brinda.

En cuanto a su etimología el término multimedia está compuesto de dos vocablos multi y media y se obtiene una unidad léxica redundante porque multi es varios y media significa varios medios. ( diccionario de Martínez de Sousa)

En otro concepto la "Multimedia es el uso de los diversos tipos de medios para transmitir, administrar o presentar información usando software y hardware para almacenar contenidos" ${ }^{8}$

La Asociación Mexicana de Multimedia y Nuevas Tecnologías (AMMYNT) a través de su presidente, el Ing. José Luis Oliva Posada, señala: La multimedia es una tendencia de mezclar diferentes tecnologías de difusión, de información, impactando varios sentidos a la vez, para lograr un efecto mayor en la comprensión del mensaje (PC WORLD, No. 117, 1993, 25).

La asociación reconoce tres ámbitos de desarrollo de multimedia y sólo a uno de ellos como tal:

1) Transmedia: Ámbito de los medios de comunicación consolidados, con un leguaje propio y un uso de costumbres diarias, donde las computadoras se destinan a la confección de mensajes

2) Intermedia: Ámbito definido por el uso de elementos de diferentes medios de comunicación para la transmisión de un mensaje, donde los medios, antes de consolidarse como tales, fueron multimedia. En esta mezcla puede no utilizarse la computadora

3) Multimedia: Ámbito de uso de la computadora en aplicaciones hechas para que el usuario final la utilice mezclando tres o más de cinco datos que se emplea en la transmisión del conocimiento formal: texto, gráficas, música, voz, imagen fija o en movimiento.

Para Héctor Schwabe, investigador de la UAM (Universidad Autónoma de México) multimedia ha existido como concepto desde hace 40 años aunque como realidad sólo desde 1989. Multimedia se define como la interacción de medios múltiples: sonido, texto, voz, video y gráficos. Multimedia es una suma de Hardware y Software en busca del mismo objetivo: humanizar la máquina. La interacción, que la multimedia exige del usuario, facilita la atención, la comprensión, y la retención de información. "Multimedia convertirá el diálogo hombremáquina en algo intuitivo, espontáneo y divertido", con las interfaces de usuario que están por incorporarse: pantallas sensibles al tacto, sistemas de reconocimiento de voz; será tan sencilla como emplear los cinco sentidos del ser humano (PC WORLD No. 118, p.27).

Multimedia, podría ser denominada como una integración libre de tecnología que extiende y expande la forma en que interactuamos con una computadora, concepto que enriquece y amplía la interacción hombre-máquina, hoy en día lo vemos manifestado en diversas

\footnotetext{
${ }^{8}$ BONILLA M.,Tania Milena. Conceptos de Multimedia.Barcelona: Sena , 2009
} 
aplicaciones que incluyen enciclopedias históricas, aventuras científicas animadas, libros de cuentos y novelas interactivas.

La clasificación de acuerdo a la intervención del usuario:

* Lineal, el usuario no tiene control sobre las acciones de la aplicación

*Interactiva, cuando se le permite controlar ciertos eventos de la aplicación

*Hipermedia, cuando tiene mayor control de la aplicación mediante el sistema de navegación.

Primacías de la multimedia con respecto a otros medios

- Interactividad

- Alfabetización audiovisual

- Información multimedia

- Versatibilidad

- Motivación

- Actividad mental continua e intensa

- Aprendizajes (menor tiempo y esfuerzo)

- Corrección inmediata

- Entornos para la expresión y la creación ${ }^{9}$

La multimedia mejora la retención de la información presentada dando paso a consultas en diccionarios, enciclopedias...

\section{Elementos que conforman la multimedia}

- TEXTO, con o sin formato, puede ser lineal o hipertexto

- GRÁFICOS, contienen una semántica que debe ser interpretada.

- GRÁFICOS MÓVILES, dan sensación de movimiento (animación)

- IMÁGENES, documentos formados por pixeles sin estructura ni semántica alguna.

- IMÁGENES MÓVILES (video) y sonidos

\section{Servicios multimedia}

Los servicios multimedia es donde el usuario proyecta la comunicación y aborda las áreas de comunicación, relaciones públicas, investigación y formación.

\footnotetext{
${ }^{9}$ SUAREZ ALONSE, Francisco José. La información del Siglo XXI. Oviedo :Universidad de Oviedo, 2011
} 
Cumplimentando así un triángulo perfecto:

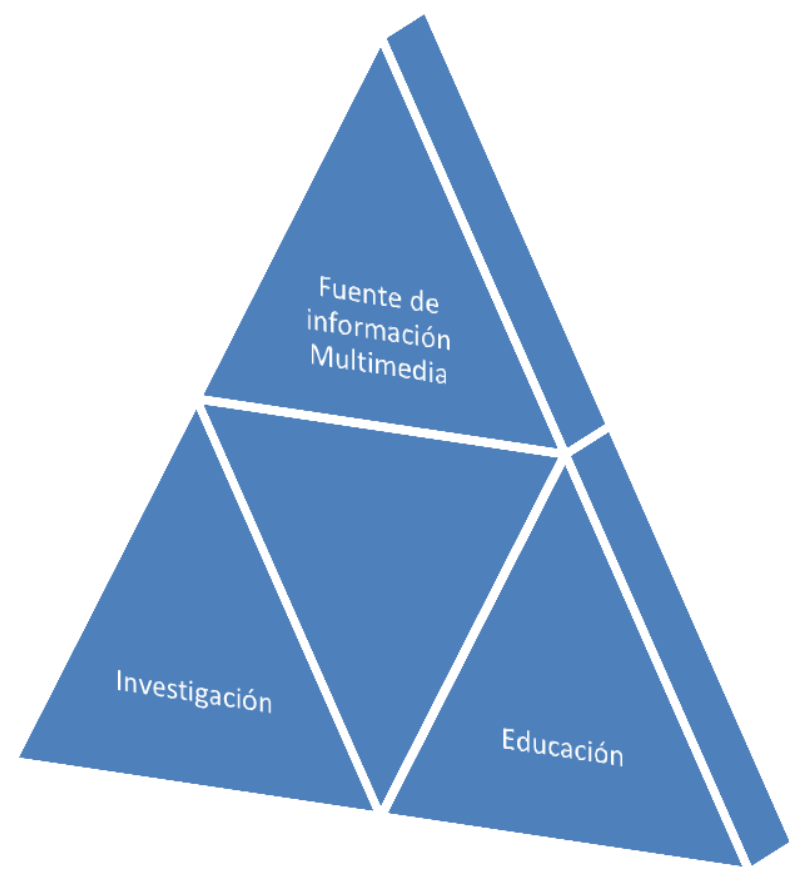

Figura 2: Servicio multimedia

Existen muchas empresas en el mundo que ofrecen servicios multimedia, se puede mencionar a Interactive Digital Multimedia Services Domain que es de carácter formativo y disponible en www.de.infowin.org/ACTS/ANALYSYS/CONCERTATION/MULTIMEDIA, o Integra Multimedia, que brinda en español proyectos educativos y se halla en www. Integra.es. Además cabe mencionar al proyecto CHRARISMA, disponible en www.transtod.com/jedi, que brinda la posibilidad de combinar en un solo soporte el libro, el CD-ROM y las actividades de los contenidos por Internet.

\section{Cuadro comparativo de bibliotecas con y sin recursos multimedia}

\begin{tabular}{|c|c|}
\hline Biblic & Biblioteca con recursos multimedia \\
\hline $\begin{array}{l}\text { Poca influencia en el trabajo educativo. } \\
\text { - Los servicios están circunscritos a la } \\
\text { atención de sala de lectura y préstamo de } \\
\text { libros. } \\
\text { infraestructura inadecuada y recursos de } \\
\text { información limitados. } \\
\text { - Imagen subvaluada ante los diversos } \\
\text { estamentos de la comunidad educativa. } \\
\text { - El personal a cargo por lo general carece } \\
\text { de formación en el área bibliotecológica y }\end{array}$ & $\begin{array}{l}\text { Plenamente integrada al trabajo } \\
\text { educativo. } \\
\text { - Es conducida por un bibliotecólogo } \\
\text { - Tiene una buena imagen, pues su labor } \\
\text { constituye un eje promotor de la } \\
\text { excelencia educativa. } \\
\cdot \text { Los servicios están estructurados en } \\
\text { función a las necesidades de información } \\
\text { de los usuarios y a las exigencias del } \\
\text { programa curricular. } \\
\text { Cuenta con variados recursos de }\end{array}$ \\
\hline
\end{tabular}


pedagógica.

El docente no vincula su trabajo pedagógico al uso de los recursos de información que posee la biblioteca.

El docente en su mayoría desconoce el uso potencial de las NTI y su aplicación en el trabajo pedagógico (aplicaciones de software, uso de material multimedia e Internet). información bibliográfica, audiovisuales,

multimedia (CD-ROM), incorpora y propicia el uso de las NTI (Internet).

. El docente incluye en su programación curricular el uso de los recursos de información.

- Produce material educativo en diversos soportes mediante la constitución de equipos de docentes de carácter interdisciplinario.

El docente, en el marco de su labor pedagógica, utiliza las NTI

\section{Disposiciones del Ministerio de Educación y Cultura Paraguay}

Dentro de la política de tecnología información y comunicación el MEC dispuso en concreción a lo mencionado en el cuadro anterior, tomando como aval legal la Carta Magna del 1992 y la Ley № 1264 General de Educación lo siguiente:

-Insumos para posibilitar el uso de la TIC

-Marcos de uso esperado

-Incentivos para el buen uso

-Monitoreo y evaluaciones

Pero se debe tener en cuenta los resultados de la Dirección de Estadísticas Encuestas y Censo para valorar los programas, atendiendo que la penetración Internet es de 3,8\%, la infraestructura tecnológica es de un $7 \%$ y la conectividad (cobertura) es de un $4 \%{ }^{10}$ En pos a lo manifestado se ofrece el detalle general arrojado por el Censo 2003:

- Aproximadamente el $76 \%$ de los hogares disponen de televisor, siendo el medio masivo de comunicación con mayor presencia en todos los departamentos.

- El 93,5\% de los hogares de Asunción y el 87,5\% de los hogares del departamento Central cuentan con televisor siendo los departamentos con mayor concentración de este bien. Los de menos concentración son San Pedro y Canendiyú (46,4\% y 48,8\% respectivamente).

- La proporción de hogares que poseen televisor y son consideradas pobres corresponde a casi dos tercios del total de hogares, 65,4\%. En todos los departamentos más del 50\% de los hogares pobres cuentan con televisor entre sus bienes excepto Canendiyú y San Pedro $(24,7 \%$ y $35,3 \%)$.

- En el área rural, 6 de cada 10 hogares cuentan con televisor, en el área urbana 9 de cada 10 hogares cuentan con dicho medio de comunicación.

${ }^{10}$ DGEEy C. 16 ago 2011 
- El porcentaje de hogares de hogares con servicio de telefonía móvil (celular) es mayor a la proporción de hogares que cuentan con servicio de telefonía fija (31,2\% y 17,4\% respectivamente).

- En los hogares de Asunción, si bien tanto la utilización de teléfono celular y teléfono línea fija como medio de comunicación en general no presenta diferencias, 51\%; entre los hogares considerados pobres el uso de la telefonía móvil se halla más extendido que la telefonía fija (26,2\% y $11,6 \%$ respectivamente).

- Entre los hogares pobres, aproximadamente el $18 \%$ de los hogares utilizan el teléfono celular como medio de comunicación, entre los hogares no pobres esta proporción asciende a $38 \%$.

- Aproximadamente el $18,7 \%$ de las viviendas asentadas en el área rural cuentan con teléfono celular, en el área urbana este porcentaje prácticamente se duplica, $40 \%$.

- El porcentaje de los hogares considerados pobres y que disponen de teléfono con línea fija no supera $5 \%$. En el área rural los hogares con tenencia de teléfono con línea fija representan el 2,1\% del total de hogares de dicha área.

- La utilización de antena parabólica como medio de acceso a la información no es frecuente; 3,7\% en el total país. En los departamentos limítrofes al Brasil como Canindeyú $(21,9 \%)$, Amambay $(13,5 \%)$ y Alto Paraná $(11,6 \%)$ su uso se halla más extendido.

- En nuestro país, 10 de cada 100 hogares cuentan con TV cable. Este servicio se concentra principalmente en Asunción ( 3 de cada 10 hogares de la capital cuentan con dicho servicio).

- El 93,7\% de los hogares carecen de computadora. Entre los hogares considerados pobres y los hogares asentados en el área rural esta proporción no supera el $1 \%$

- Los hogares con computadora y servicio de Internet no alcanza el $2 \%$, este servicio se concentra en Asunción (11,1\%). ${ }^{11}$

Por lo expuesto el Paraguay avanza con pequeños pasos para paliar la brecha digital e incorporar en forma efectiva las herramientas tecnológicas, tomando una posición para estar preparados para luchar contra la exclusión.

\section{Aspecto legal}

Desde una perspectiva legal, a menudo es esencial distinguir entre diferentes manifestaciones de un ente de información, y la importancia de las mismas para la tomas de decisiones en una reconstrucción de actos dados con anterioridad. Los derechos de autor, las licencias de uso, condiciones de reutilización y la autorización para usos parciales forman parte importante de los aspectos legales del documento multimedia y constituyen elementos importantes que el usuario debe conocer, incluso antes de tener acceso al documento, para no perder tiempo si corresponde tramitar alguna licencia de uso. Como afirma Desantes Guanter: "El derecho de

\footnotetext{
${ }^{11}$ Dirección General de Estadísticas Encuestas y Censo. 2003. Encuesta permanente de hogares.
} 
autor protege la expresión de lo creado mediante la publicación por cualquier medio, lo que presupone su incorporación a gran variedad de soportes, tangibles o intangibles, actualmente en funcionamiento o que se inventen o se utilicen en el futuro"

Asimismo, la tesis doctoral de María Isabel López Gar presentada en julio de 2010 en México, determina que "el análisis del derecho a la información, a estar informado, no puede desvincularse del análisis del régimen de la explotación de los medios audiovisuales y de la propia delimitación del concepto de medio audiovisual, atendiendo en todo momento al avance tecnológico que obliga a configurar un marco jurídico adaptado a la realidad del momento en que Internet tiene un papel fundamental", y el 'Servicio público, libre competencia y derecho a la información en la oferta de contenidos audiovisuales' .

\section{Función del bibliotecario en el cambio educativo}

Para que todo lo citado anteriormente tenga el alcance deseado es gran protagonista el profesional de la información tomando funciones tales como:

- Articular de los programas de alfabetización informacional con el currículo académico.

- Poseer técnicas pedagógicas que le permitan ser versátiles en las diversas oportunidades para la formación de usuarios

- Difundir y preparar materiales específicos en apoyo al currículo

Cualidades personales del profesional de la información

- Comprometido con la excelencia del servicio

- Visión amplia-busca asociaciones y alianzas

- Crea ambiente de respeto mutuo y confianza

- Poseer habilidades para comunicarse

- Trabajar en equipo

- Tener espíritu de líder

- Comprometido con la formación continua

- Habilidades en el uso de tecnologías

- Ser cooperativo y solidario

- Ser flexible y tener actitud positiva ante los cambios

- Responde a las exigencias del mercado laboral.

En líneas generales el Bibliotecólogo tiene la misión y el desafío en esta sociedad del conocimiento o sociedad de la información que es la de aprovechar la tecnología del mundo globalizado y reducir en la medida de las posibilidades la brecha entre los informados ricos e 
informados pobres, logrando así la participación de la sociedad de la información con cultura, capacidad y desarrollo de los usuarios.

Indicadores positivos de capacidad

Apuntando en el logro positivo la capacidad de:

- Determinar la magnitud de la información que necesita

- Acceso efectivo y eficiente

- Evaluación crítica y reflexiva

- Comprensión de aspectos económicos, legales éticos y sociales en relación al uso y acceso a la información

Competencias del profesional de la información en contextos educativos

Para poder participar en la definición y en el apoyo a los nuevos modelos de la práctica educacional y la formación continua, los profesionales de la información necesitan oportunidades para expandir su conocimiento y experticia en nuevas áreas, por ejemplo, en relación con aspectos relevantes de las teorías del aprendizaje y los usos de las tecnologías educativas, así como en trabajo multidisciplinario e innovación, porque no sólo deben reunir determinados conocimientos y competencias en el uso de la información, desde la toma de decisiones y estrategias de búsqueda hasta la evaluación de las fuentes, sino que también deben ser capaces de actuar como facilitadores del aprendizaje, al integrar estos procesos en el trabajo en el aula.

En pos a estas cualidades y actitudes el logrará que los usuarios adquieran un aprendizaje significativo, recordando que cuando se aplican todos los sentidos en el proceso de enseñanza aprendizaje.

\section{METODOLOGIA}

El estudio que propone este trabajo, es cuanti-cualitativo. En el se analizan los factores que obstaculizan y facilitan el desarrollo de la información audiovisual y multimedia en bibliotecas con el uso efectivo y eficiente por parte de los usuarios favoreciendo su aprendizaje integral.

Y la consideración del rol protagónico del profesional de la información como gerente de innovación y desarrollo. El diseño es no experimental, ya que no se manipula variables, sino la observación del fenómeno y como se da en el contexto de la biblioteca, para luego analizarlo.

Para la valuación del impacto de la aplicación en el proceso cuantitativo se aplica el modelo Ticometría , expuesto por Fazio y Goldstein en 2003

Se procede a la toma de la encuesta a los usuarios de las bibliotecas que presten o posean servicios sobre la información audiovisual y multimedia, tomando moda, mediana, histograma y curvas de dispersión a través del programa Excel de Microsoft Office con los datos obtenidos.

Las variables cualitativas serán tomadas en porcentaje y las cuantitativas en frecuencias. 
Alcance y limitaciones

Su alcance es temporal, los datos serán recogidos y analizados en un periodo determinado. El estudio dará lugar a investigaciones evaluativas tendientes a enjuiciar y apreciar la aplicación de la tecnología como herramienta para la información pronta y cierta. La locación será la ciudad de San Lorenzo, con los 53 CRA públicos de su jurisdicción del radio urbano y rural.

\section{Análisis de los resultados}

Los resultados a obtener podrán facilitar la aplicación y uso de las nuevas tecnologías tomando los datos obtenidos en pos a capacitaciones y nominales para el énfasis de incursión y apoyo, beneficiando a la comunidad educativa san lorenzana en primera instancia y por replicas en las demás ciudades del Paraguay.

La atención especial dada al Bibliotecario como facilitador y dinamizador de un Centro de Recursos para el Aprendizaje, con responsabilidad de formar y educar para el progreso de la sociedad del conocimiento.

Puntos a tener en cuenta para el análisis:

Infraestructura, acceso, uso, capacitación, aplicaciones pedagógicas, percepción de uso, mantenimiento, financiamiento, recursos, apoyo, impacto, planeación, actitud hacia la tecnología, difusión.

\section{RESULTADO Y DISCUSIÓN \\ Conclusión y resultados parciales}

La multimedia, será denominada como una integración libre para la tecnología, que extiende y expande la forma en que interactuamos con una computadora, concepto que enriquece y amplía la interacción hombre-máquina, hoy manifestado en diversas aplicaciones que incluyen enciclopedias históricas, aventuras científicas animadas y libros de cuentos y novelas interactivas.

Los muchos elementos desplegados en beneficio de la efectividad de la información; por ejemplo, las tecnologías semánticas sin dudar, al asignar el significado correcto a los significantes constituye un reto cardinal, pero no se debe olvidar la semiótica particular de la pantalla que casi todos tenemos delante, podemos seguramente hablar de la semiótica de la información multimedia cotidiana en beneficio a minimizar la brecha digital de países como el nuestro.

El rol del bibliotecario que actúa como nexo entre el mundo de la información y los usuarios, creando una cultura de individuos con capacidad de trabajar con información para su desarrollo integral.

Transportar las formulaciones teóricas hacia propuestas concretas que permitan a los bibliotecarios responsabilidades formativas de aplicaciones para desempeñar con eficacia las acciones en la alfabetización informacional, en el logro de un usuario que interprete, critique y reflexiones sobre la información dada. 


\section{REFERENCIAS BIBLIOGRAFICAS}

AUSUBEL, J.. 1983.. Psicología educativa: un punto de vista cognoscitivo. 2ª .ed México: Trillas, $213 \mathrm{p}$.

BARANDA DEL CAMPO, C. 2009. El documentalista de Información de actualidad, formación y profesión. Madrid: Universidad Complutense.

La biblioteca escolar como centro de recursos parra el aprendizaje. 2006. Asunción : MEC-, $131 \mathrm{p}$.

BONILLA M., T. M. 2009. Conceptos de Multimedia. Barcelona

CASTELL, M. 1991. La industria de las tecnologías de la información. Madrid: Fundesco.

CEBRIÁN HERREROS, M.. 1995 Información audiovisual y educación. Madrid: UNED. p 485-495.

Cuadernos de documentación multimedia. 2009. Madrid: Universidad Complutense, Departamento de Biblioteconomía y documentación.

ENEBRAL FERNANDEZ, J. 2004. La información del Siglo XXI, multimedia.

IFLA (International Federation of Library Associations and Institutions). 2004. Directrices para materiales audiovisuales y multimedía en bibliotecas y otras instituciones. (S.L.): IFLA Professional reports 84. 24 p.

LOPEZ YEPES, A. 1993. Manual de documentación audiovisual. Pamplona: Eunsa.

MEC (MINISTERIO DE EDUCACIÓN Y CULTURA).1999 Plan estratégico de la reforma educativa. 3… Ed. Asunción: Consejo asesor de la reforma educativa,

PEREZ VELA, E. R. 2000. De biblioteca escolar a centro de recursos multimediales construyendo un modelo. Lima: ABLA.

Plan Estratégico de Educación Paraguay 2020-actualizando bases para un pacto social.2008 Asunción: MEC.

SUAREZ ALONSE, F. J. 2011 La información del Siglo XXI. Oviedo: Universidad de Oviedo

Las tecnologías y el mundo digital: desafíos pedagógicos para la nueva escuela pública. 2010. Asunción: MEC-CLLE, 78 p.

TUVILLA RAYO, J.. Reformas educativas, transversalidad y derechos humanos. Madrid: Asociación Mundial para la Escuela de Paz, 2000. 


\section{Hemeroteca}

ALBA PASTOS, C. 1998. Recursos y materiales didácticos para el siglo XXI: multimedia, telemática y otras tecnologías vestidas de seda. Revista Complutense de Educación.(ES) Vol. 9, no 1, p 15-28.

Análisis e impacto de nuevas tecnologías en el desempeño de estudiantes. CONACYT, 2009,(PY) p. 37-39

Aulas conectadas. Revista del Ministerio de Educación de la Nación, 5ta. Época set. 2010. ( AR)p.25-28

BARCELO LLAUGER, M.1988. Gestión de la información, del cambio y del conocimiento. El profesional de la información,(ES) vol. 7, nº5, mayo 1988.

Buscando formar lectores críticos .Desde el aula: un espacio abierto.(AR) no16, p 30-33

BRUCE ROYAN, M. 2004. Directrices para materiales audiovisuales y multimedia en bibliotecas y otras instituciones. The Hagur. IFLA headquarters, IFLA Professional Reports : p 64-84

CALVO, E. 2011. información audiovisual y educación. (ES)Etic@net, año 9, no10, jun.

CALDERON CRUZ, M, CSOBAN, E. 2010. Elementos para un programa de alfabetización informacional: la autoeficiencia hacia el uso de la computadora.(VN) Caracas: DialnetBiblios, no 37 .

CASTRO ESCAMILLA, M.2010. El profesional de la información. Biblios revista electrónica de bibliotecología, archivología y museología, no 37 .

COVADONGA R., DELGADO, JL., SATRE, T. 2010. Accesibilidad a los contenidos educativos audiovisuales. (ES). RIED (Revista iberoamericana de educación a distancia). Vol 13, no 2.

GOMEZ HERNANDEZ, J.A. 2008. Las metáforas sobre el mundo de la información y los bibliotecarios.(ES). Universidad de Murcia, vol.17,nํ3,p. 340-343.

HERNANDEZ, L. 2007. Multimedia, mi primera clase 1.0. ACIMED (CU).vol16, nํ2, p1-6

KOZAK, D.. 2010. Llegaron las netbooks. El monitor de la educación,(CH) nํ26, p 29-32

MARTÍN, S.G.2009. Bibliotecarios de sistemas una especialización con futuro.(AR) Universidad Católica de Córdoba, nํ21, p.69-84. (Latinet)

MORDUCHOWICZ, R. 2009. Bibliotecas integradas.(AR). Vol17, no 32, p131-138.

PEREZ ALARCON, A., SERRANO MUÑOZ, J. 1999. Tecnologias de información aplicadas a los servicios bibliotecarios (ES)Cuaderno de documentación multimedia, no8.

PEREZ BURGER, M. 2010.Plan CEIBAL, una ventana al mundo. El monitor de la educación,(UY) no 26, p 39-40. 
RAJAN, B., CREMER, M..2004. Directrices para materiales audiovisuales y multimedia en bibliotecas y otras instituciones. IFLA Profesional Report.(MX) no 84 (EBSCO)

RECIO, J.C. 1999. Fuentes de información, educación y proyectos de investigación multimedia. (ES) Cuaderno de documentación multimedia, no․

RIART MONTANER, LUIS ALBERTO. 2010 La ciencia, la tecnología y la innovación para el desarrollo : un desafío complejo desde el interrogante pedagógico. CONACYT-PROCIT 2008/2009,(PY) p.4-5

Tesis

CABRERIZO GARCIA, C., 1995. La biblioteca escolar en la educación anglosajona. Tesis (doctorado). Madrid: Universidad Complutense de Madrid (Dialnet)

MARTINEZ MÉNDEZ, F.J.,2006. Propuesta y desarrollo de un modelo para la evaluación de la recuperación de información en INTERNET. Tesis (doctorado), Murcia (Es): Universidad de Murcia (Dialnet)

MARTÍNEZ USERO, J.A, 1999.Estudio, análisis y diseño de una guía metodológica para la creación de servicios de información tecnológica, difusión de la I+D y gestión de la innovación. Tesis (doctorado) Madrid (ES): Universidad Complutense de Madrid (Dialnet)

NAUMIS PEÑA, C.. 2002. Información audiovisual multimedia sobre contenidos educativos. Tesis (doctorado). Madrid (ES): Universidad Complutense. Facultad de Ciencias de la Información. Departamento Biblioteca y Documentación. 233p.(EBSCO)

PINEDA, J.M. 2010. El nuevo rol del bibliotecólogo en la sociedad de la información. Tesis(Licenciatura) Córdoba (AR): Universidad Nacional de Córdoba..(Dialnet)

ROJAS BENITEZ, J.L. 2001. Herramientas para la evaluación de los servicios de información en instituciones cubanas. Tesis (doctorado). Habana (CU): Universidad de la Habana, Facultad de Comunicación.

\section{Electrónicos}

Audiovisuales.(en línea) Consultado 11 ago 2011. Disponible en: www.arandurape.edu.py

Compromiso de Túnez y programas de acciones de Túnez para la Sociedad de la Información (en línea). Túnez: Cumbre de la Sociedad de la Información,2005. Consultado: 28 set 2011. Disponible en : http://www.itu.int/wsis/documents/index2-es.html

BAWDEN, D. Revisión de los conceptos de alfabetización informacional y alfabetización digital (en línea) Consultado 27 set 2011. Disponible en www.um.es/fccd/anales/ad05/ad0500.html

Los desafíos de la universalización y la calidad de la educación.(en línea), Consultado 25 set 2011. Disponible en: www.oei.es/pdf2/desafios-universalizacion-calidad-educacionparaguay.pdf. 
FAZIO, M.E., GOLDSTEIN, M. Deconstrucción de las principales metodologías internacionales. (en línea) Consultado 12 oct 2011. Disponible en: www. Funredes.org/olística.

FOGLIENI, O. Como cambia los servicios de la biblioteca con el uso de la multimedia en el trabajo global.(en línea) Consultado 30 set. 2011. Disponible en: http:// archive.ifla.org/iv/ifla63/63fogo.htm

GOMEZ HERNANDEZ, J.A. La alfabetización informacional como servicio de las bibliotecas. (en línea). Consultado 25 set 2011. Disponible en: www.abgra.org.ar/rnb36/igomezalfin.ppt

Hacia el centenario de la escuela nueva de Ramón Indalecio Cardozo. (en línea) Consultado el $10 \quad$ oct 2011. Disponible en: htt://planipolis.iiep.unesco.org/upload/paraguay/paraguay_plan_educacional_2024

IFLA. Escuela, filosofía y reforma.(en línea) Consultado 30 set 2011. Disponible en: www.ifla.org/publications/guidelines-for-audivisual-and-multimedia-materiales-inlibraries.

La multimedia en educación.(en línea) Consultado 15 set 2011. Disponible en: http// leidyrobn.blog.diario.com

Manual para el acceso y búsqueda de información.(en línea) Consultado 25 set 2011 Disponible en: www. biblio.iteso.mx/biblioteca.

OTLET, P.. Documentación multimedia tratamiento.(en línea) Consultado 10 ago 2011. Disponible en: www. Eprmts.ucm.es / tesis.

SANCHEZ TARRAGO, N. El profesional de la información en los contextos educativos de la sociedad del aprendizaje: espacios y competencias (en línea) Consultado 29 set 2011. Disponible en http//bvs.sld.cu/revistas/aci/vol13-2-05.htm

TIC: nuevas tecnologías y educación. (en línea)Consultado: 11 ago 2011. Disponible en: www.aci.es/ties.php. 